TAIWANESE JOURNAL OF MATHEMATICS

Vol. 11, No. 1, pp. 27-42, March 2007

This paper is available online at http://www.math.nthu.edu.tw/tjm/

\title{
WEAK AND STRONG CONVERGENCE FOR COMMON FIXED POINTS OF A PAIR OF NONEXPANSIVE AND ASYMPTOTICALLY NONEXPANSIVE MAPPINGS
}

\author{
Zeqing Liu, Chi Feng, Jeong Sheok Ume and Shin Min Kang
}

\begin{abstract}
In this paper, we establish some weak and strong convergence theorems of modified Ishikawa iteration methods with errors with respect to a pair of nonexpansive and asymptotically nonexpansive mappings in uniformly convex Banach spaces. The results presented in this paper generalize, improve and unify a few results due to Chang [2], Osilike and Aniagbosor [10], Rhoades [11] and Schu [13,14] and others.
\end{abstract}

\section{INTRODUCTION}

In 1972, Goebel and Kirk [4] introduced the concept of asymptotically nonexpansive mappings and proved that if $K$ is a nonempty closed bounded subset of a uniformly convex Banach space $E$, then every asymptotically nonexpansive self-mapping on $K$ has a fixed point. After that, a number of authors studied a few iterative approximation methods of fixed points for asymptotically nonexpansive mappings. In 1991, Schu [13], [14] introduced the modified Ishikawa iteration methods and modified Mann iteration methods and proved that the modified Mann iteration sequence converges strongly to some fixed points of asymptotically nonexpansive mappings in Hilbert spaces. Rhoades [11] extended the results in [13] to uniformly convex Banach spaces and to modified Ishikawa iteration methods. Chang [2], Liu, Kim and Kim [6], Liu, Kim and Chun [7], Liu and Kang [8] and Osilike and Aniagbosor [10] and others also established some strong and weak convergence

Received October 27, 2004, revised August 2, 2005.

Communicated by Wen-Wei Lin.

2000 Mathematics Subject Classification: 47H05, 47H10, 47H15.

Key words and phrases: Nonexpansive mapping, Asymptotically nonexpansive mapping, Common fixed points, Modified Ishikawa iteration method with errors with respect to a pair of mappings.

This work was supported by the Science Research Foundation of Educational Department of Liaoning Province (2004C063) and the Korea Research Foundation Grant funded by the Korea Government (MOEHRD, Basic Research Promotion Fund) (KRF-2006-312-C00026). 
theorems of modified Ishikawa iteration methods with errors and three-step iteration methods with errors for asymptotically nonexpansive mappings. Very recently, Agarwal, Cho, Li and Hunag [1] have studied convergence of the Ishikawa iteration process with errors for a couple of quasi-contractive mappings in $q$-uniformly smooth Banach spaces.

In this paper, we introduce a new iterative method, called modified Ishikawa iteration method with errors with respect to a pair of mappings, and establish some strong and weak convergence theorems of the modified Ishikawa iteration method with errors with respect to a pair of nonexpansive and asymptotically nonexpansive mappings in nonempty closed convex subsets of uniformly convex Banach spaces. The results presented in this paper generalize, improve and unify a few results due to Chang [2], Osilike and Aniagbosor [10], Rhoades [11] and Schu [13, 14] and others.

\section{PReLIMINARIES}

Let $E$ be a uniformly convex Banach space, $K$ be a nonempty subset of $E$ and $S, T: K \rightarrow K$ be two mappings. $F(S, T)$ denotes the set of common fixed points of $S$ and $T, I$ stands for the identity mapping on $E$. Let $J: E \rightarrow 2^{E}$ be the normalized duality mapping defined by

$$
J(x)=\left\{f \in E^{*},\langle x, f\rangle=\|x\| \cdot\|f\|,\|f\|=\|x\|\right\}, \forall x \in E .
$$

Let us recall the following concepts and results.

Definition 2.1 [3]. A mapping $T: K \rightarrow K$ is said to be

(i) asymptotically nonexpansive if there exists a sequence $\left\{k_{n}\right\}_{n \geq 1} \subset[1, \infty)$ with $\lim _{n \rightarrow \infty} k_{n}=1$ such that

$$
\left\|T^{n} x-T^{n} y\right\| \leq k_{n}\|x-y\|, \quad \forall x, y \in K, n \geq 1 ;
$$

(ii) nonexpansive if

$$
\|T x-T y\| \leq\|x-y\|, \quad \forall x, y \in K ;
$$

(iii) uniformly $L$-Lipschitzian if there exists a constant $L \geq 1$ satisfying

$$
\left\|T^{n} x-T^{n} y\right\| \leq L\|x-y\|, \quad \forall x, y \in K, n \geq 1 ;
$$

(iv) semi-compact if $K$ is closed and for any bounded sequence $\left\{x_{n}\right\}_{n \geq 1}$ in $K$ with $\lim _{n \rightarrow \infty}\left\|x_{n}-T x_{n}\right\|=0$, there exists a subsequence $\left\{x_{n_{i}}\right\}_{i \geq 1} \subset$ $\left\{x_{n}\right\}_{n \geq 1}$ and $x \in K$ such that $\lim _{i \rightarrow \infty} x_{n_{i}}=x$. 
It is well known that each nonexpansive mapping is asymptotically nonexpansive with $k_{n} \equiv 1$ for all $n \geq 1$, and each asymptotically nonexpansive mapping with a sequence $\left\{k_{n}\right\}_{n \geq 1} \subset[1, \infty)$ and $\lim _{n \rightarrow \infty} k_{n}=1$ is uniformly $L$-Lipschitzian with $L=\sup \left\{k_{n}: n \geq 1\right\}$, and the converses are not true.

Definition 2.2. A mapping $T$ with domain $D(T)$ and range $R(T)$ in $E$ is called demiclosed at a point $p \in D(T)$ if whenever $\left\{x_{n}\right\}_{n \geq 1}$ is a sequence in $E$ which converges weakly to a point $x \in E$ and $\left\{T x_{n}\right\}_{n \geq 1}$ converges strongly to $p$, then $T x=p$.

Definition 2.3 [9]. A Banach space $E$ is called to satisfy Opial's condition if for each sequence $\left\{x_{n}\right\}_{n \geq 1}$ in $E$ which converges weakly to a point $x \in E$

$$
\liminf _{n \rightarrow \infty}\left\|x_{n}-x\right\|<\liminf _{n \rightarrow \infty}\left\|x_{n}-y\right\|, \quad \forall y \in E-\{x\} .
$$

Definition 2.4. Let $K$ be a nonempty convex subset of a normed linear space $E$ and $S, T: K \rightarrow K$ be two mappings. For an arbitrary $x_{1} \in K$, the modified Ishikawa iteration sequence with errors $\left\{x_{n}\right\}_{n \geq 1}$ with respect to $S$ and $T$ is defined by

$$
\begin{aligned}
y_{n} & =a_{n}^{\prime} S x_{n}+b_{n}^{\prime} T^{n} x_{n}+c_{n}^{\prime} v_{n}, \\
x_{n+1} & =a_{n} S x_{n}+b_{n} T^{n} y_{n}+c_{n} u_{n}, \quad \forall n \geq 1,
\end{aligned}
$$

where $\left\{u_{n}\right\}_{n \geq 1}$ and $\left\{v_{n}\right\}_{n \geq 1}$ are given bounded sequences in $K,\left\{a_{n}\right\}_{n \geq 1},\left\{b_{n}\right\}_{n \geq 1}$, $\left\{c_{n}\right\}_{n \geq 1},\left\{a_{n}^{\prime}\right\}_{n \geq 1},\left\{b_{n}^{\prime}\right\}_{n \geq 1}$ and $\left\{c_{n}^{\prime}\right\}_{n \geq 1}$ are sequences in $[0,1]$ satisfying

$$
a_{n}+b_{n}+c_{n}=a_{n}^{\prime}+b_{n}^{\prime}+c_{n}^{\prime}=1, \forall n \geq 1 .
$$

Remark 2.1. In case $S=I$ in (2.2), then the sequence $\left\{x_{n}\right\}_{n \geq 1}$ generated in (2.1) reduces to the usual modified Ishikawa iteration sequence with errors.

Remark 2.2. For the usual Ishikawa iteration process with errors, Rhoades [12] pointed out that "Not knowing the precise values $u_{n}$ and $v_{n}$ makes it impossible to continue the iteration process". In order to solve the problem, that is, in order to continue the iteration process, we have to know the precise values $u_{n}$ and $v_{n}$ before calculating the usual Ishikawa iteration process with errors. Hence we state that the sequences $\left\{u_{n}\right\}_{n \geq 1}$ and $\left\{v_{n}\right\}_{n \geq 1}$ in the Definition 2.4 are given bounded sequences in $K$.

Lemma 2.1 ([5]). Let E be a Banach space satisfying Opial's condition and $K$ be a nonempty closed convex subset of $E$. If $T: K \rightarrow K$ is an asymptotically nonexpansive mapping, then $I-T$ is demiclosed at zero. 
Lemma 2.2 ([14]). Let $E$ be a uniformly convex Banach space, $\left\{t_{n}\right\}_{n \geq 1} \subseteq$ $[b, c] \subset(0,1),\left\{x_{n}\right\}_{n \geq 1}$ and $\left\{y_{n}\right\}_{n \geq 1}$ be sequences in $E$. If $\lim _{\sup _{n \rightarrow \infty}}\left\|x_{n}\right\| \leq a$, $\limsup _{n \rightarrow \infty}\left\|y_{n}\right\| \leq a$ and $\lim _{n \rightarrow \infty}\left\|t_{n} x_{n}+\left(1-t_{n}\right) y_{n}\right\|=a$ for some constant $a \geq 0$, then $\lim _{n \rightarrow \infty}\left\|x_{n}-y_{n}\right\|=0$.

Lemma 2.3 ([3]). Let $E$ be a normed linear space. Then

$$
\|x+y\|^{2} \leq\|x\|^{2}+2\langle y, j(x+y)\rangle, \forall x, y \in E, j(x+y) \in J(x+y) .
$$

Lemma 2.4 ([15]). Let $p>1$ and $r>0$ be two constants. Then a Banach space $E$ is uniformly convex if and only if there exists a continuous and strictly increasing convex function $g:[0, \infty) \rightarrow[0, \infty)$ with $g(0)=0$ such that

$$
\|a x+(1-a) y\|^{p} \leq a\|x\|^{p}+(1-a)\|y\|^{p}-w_{p}(a) g(\|x-y\|)
$$

for each $a \in[0,1]$ and $x, y \in B(\theta, r)=\{u:\|u\| \leq r$ and $u \in E\}$, where

$$
w_{p}(a)=a^{p}(1-a)+a(1-a)^{p} .
$$

Lemma 2.5 ([10]). Let $\left\{a_{n}\right\}_{n \geq 1},\left\{b_{n}\right\}_{n \geq 1}$ and $\left\{c_{n}\right\}_{n \geq 1}$ be sequences of nonnegative numbers satisfying the inequality

$$
a_{n+1} \leq\left(1+c_{n}\right) a_{n}+b_{n}, \quad \forall n \geq 1 .
$$

If $\sum_{n=1}^{\infty} c_{n}<\infty$ and $\sum_{n=1}^{\infty} b_{n}<\infty$, then $\lim _{n \rightarrow \infty} a_{n}$ exists. In particular, if $\left\{a_{n}\right\}_{n \geq 1}$ has a subsequence which converges to zero, then $\lim _{n \rightarrow \infty} a_{n}=0$.

\section{MAin Results}

Lemma 3.1. Let $K$ be a nonempty convex subset of a normed linear space $E$. Let $S: K \rightarrow K$ be a mapping and $T: K \rightarrow K$ be uniformly L-Lipschitzian. Then

$$
\begin{gathered}
\left\|x_{n+1}-T x_{n+1}\right\| \leq\left\|x_{n+1}-T^{n+1} x_{n+1}\right\|+L\left(L^{2}+2 L+2\right)\left\|x_{n}-T^{n} x_{n}\right\| \\
+L(L+1)\left[(L+1)\left\|S x_{n}-x_{n}\right\|+c_{n}\left\|u_{n}-x_{n}\right\|+L b_{n} c_{n}^{\prime}\left\|v_{n}-x_{n}\right\|\right]
\end{gathered}
$$

for any $n \geq 1$, where $\left\{x_{n}\right\}_{n \geq 1}$ is defined by (2.1).

Proof. Set $A_{n}=\left\|x_{n}-T^{n} x_{n}\right\|, B_{n}=\left\|S x_{n}-x_{n}\right\|$ for each $n \geq 1$. It follows that

$$
\left\|y_{n}-x_{n}\right\| \leq a_{n}^{\prime} B_{n}+b_{n}^{\prime} A_{n}+c_{n}^{\prime}\left\|v_{n}-x_{n}\right\|,
$$




$$
\begin{aligned}
\left\|x_{n+1}-x_{n}\right\| \leq & a_{n} B_{n}+b_{n}\left(\left\|T^{n} y_{n}-T^{n} x_{n}\right\|\right. \\
& \left.+\left\|T^{n} x_{n}-x_{n}\right\|\right)+c_{n}\left\|x_{n}-u_{n}\right\| \\
\leq & a_{n} B_{n}+b_{n} L\left\|x_{n}-y_{n}\right\|++b_{n} A_{n}+c_{n}\left\|x_{n}-u_{n}\right\|
\end{aligned}
$$

and

$$
\begin{aligned}
\left\|x_{n+1}-T x_{n+1}\right\| \leq & A_{n+1}+L\left\|T^{n} x_{n+1}-x_{n+1}\right\| \\
\leq & A_{n+1}+L\left(\left\|T^{n} x_{n+1}-T^{n} x_{n}\right\|\right. \\
& \left.+\left\|T^{n} x_{n}-x_{n}\right\|+\left\|x_{n}-x_{n+1}\right\|\right) \\
\leq & A_{n+1}+L^{2}\left\|x_{n+1}-x_{n}\right\|+L\left\|T^{n} x_{n}-x_{n+1}\right\| \\
\leq & A_{n+1}+L(L+1)\left\|x_{n+1}-x_{n}\right\|+L A_{n}
\end{aligned}
$$

for all $n \geq 1$. Substituting (3.1) and (3.2) into (3.3), we obtain that

$$
\begin{aligned}
\left\|x_{n+1}-T x_{n+1}\right\| \leq & A_{n+1}+L^{2}(L+2 L+2) A_{n}+L(L+1)^{2} B_{n} \\
& +L(L+1)\left[c_{n}\left\|u_{n}-x_{n}\right\|+L b_{n} c_{n}^{\prime}\left\|v_{n}-x_{n}\right\|\right]
\end{aligned}
$$

for any $n \geq 1$. This completes the proof of Lemma 2.1 .

Remark 3.1. Lemma 1.2 in [10], Lemma 1.4 in [11] and Lemma 1.4 in [14] are special cases of Lemma 3.1.

Lemma 3.2. Let $K$ be a nonempty convex subset of a normed linear space $E$. Let $S: K \rightarrow K$ be a nonexpansive mapping and $T: K \rightarrow K$ be an asymptotically nonexpansive mapping with a sequence $\left\{k_{n}\right\}_{n \geq 1} \subseteq[1, \infty)$ satisfying $\lim _{n \rightarrow \infty} k_{n}=$ 1 and $F(S, T) \neq \emptyset$. If the following conditions

$$
\begin{aligned}
& \sum_{n=1}^{\infty} c_{n}<\infty, \\
& \sum_{n=1}^{\infty} b_{n} c_{n}^{\prime}<\infty
\end{aligned}
$$

and

$$
\sum_{n=1}^{\infty}\left(k_{n}-1\right)<\infty
$$

hold, then $\lim _{n \rightarrow \infty}\left\|x_{n}-q\right\|$ exists for any $q \in F(S, T)$, where $\left\{x_{n}\right\}_{n \geq 1}$ is defined by (2.1). 
Proof. Let $q \in F(S, T)$. Since $\left\{u_{n}-q\right\}_{n \geq 1}$ and $\left\{v_{n}-q\right\}_{n \geq 1}$ are bounded, it follows that $M=\sup \left\{\left\|u_{n}-q\right\|,\left\|v_{n}-q\right\|: n \geq 1\right\}<\infty$. In view of (2.1) we infer that

$$
\begin{aligned}
\left\|x_{n+1}-q\right\| \leq & a_{n}\left\|x_{n}-q\right\|+b_{n} k_{n}\left\|y_{n}-q\right\|+c_{n}\left\|u_{n}-q\right\| \\
\leq & a_{n}\left\|x_{n}-q\right\|+b_{n} k_{n}\left(a_{n}^{\prime}\left\|x_{n}-q\right\|+b_{n}^{\prime} k_{n}\left\|x_{n}-q\right\|\right. \\
& \left.\quad+c_{n}^{\prime}\left\|v_{n}-q\right\|\right)+c_{n} M \\
\leq & {\left[a_{n}+b_{n} k_{n}\left(a_{n}^{\prime}+b_{n}^{\prime} k_{n}\right)\right]\left\|x_{n}-q\right\|+\left(b_{n} c_{n}^{\prime} k_{n}+c_{n}\right) M } \\
\leq & {\left[1-b_{n}+b_{n} k_{n}\left(1-b_{n}^{\prime}+b_{n}^{\prime} k_{n}\right)\right]\left\|x_{n}-q\right\|+\left(b_{n} c_{n}^{\prime} k_{n}+c_{n}\right) M } \\
\leq & {\left[1+\left(k_{n}-1\right)\left(1+k_{n}\right)\right]\left\|x_{n}-q\right\|+\left(b_{n} c_{n}^{\prime} k_{n}+c_{n}\right) M }
\end{aligned}
$$

for each $n \geq 1$. It follows from (3.4)-(3.7) and Lemma 2.5 that $\lim _{n \rightarrow \infty}\left\|x_{n}-q\right\|$ exists. This completes the proof.

Remark 3.2. Lemma 3.2 generalizes Lemma 3 in [10] and Lemma 1.2 in [14].

Lemma 3.3. Let $K$ be a nonempty convex subset of a uniformly convex Banach space $E$. Let $S: K \rightarrow K$ be a nonexpansive mapping and $T: K \rightarrow K$ be an asymptotically nonexpansive mapping with a sequence $\left\{k_{n}\right\}_{n \geq 1} \subseteq[1, \infty)$ satisfying $\lim _{n \rightarrow \infty} k_{n}=1, F(S, T) \neq \emptyset,(3.4)-(3.6)$ and

$$
\|x-T y\| \leq\|S x-T y\|, \forall x, y \in K .
$$

If the sequence $\left\{x_{n}\right\}_{n \geq 1}$ satisfies (2.1),

$$
\limsup _{n \rightarrow \infty} b_{n}^{\prime} k_{n}<1
$$

and

$$
0<a \leq b_{n} \leq b<1, \forall n \geq 1,
$$

where $a$ and $b$ are constants, then $\lim _{n \rightarrow \infty}\left\|x_{n}-S x_{n}\right\|=\lim _{n \rightarrow \infty}\left\|x_{n}-T x_{n}\right\|=0$.

Proof. Let $q \in F(S, T)$. Lemma 3.2 ensures that $\lim _{n \rightarrow \infty}\left\|x_{n}-q\right\|$ exists. Set $\lim _{n \rightarrow \infty}\left\|x_{n}-q\right\|=d$. Since $\left\{u_{n}\right\}_{n \geq 1}$ and $\left\{v_{n}\right\}_{n \geq 1}$ are bounded sequences, it follows that

$$
M=\sup \left\{\left\|u_{n}-q\right\|,\left\|v_{n}-q\right\|,\left\|x_{n}-v_{n}\right\|,\left\|x_{n}-u_{n}\right\|: n \geq 1\right\}<\infty .
$$

Observe that

$$
\begin{aligned}
\lim _{n \rightarrow \infty}\left\|x_{n+1}-q\right\|= & \lim _{n \rightarrow \infty}\left\|\left(1-b_{n}-c_{n}\right) S x_{n}+b_{n} T^{n} y_{n}+c_{n} u_{n}-q\right\| \\
= & \lim _{n \rightarrow \infty} \|\left(1-b_{n}\right)\left[S x_{n}-q-c_{n}\left(S x_{n}-u_{n}\right)\right] \\
& +b_{n}\left[T^{n} y_{n}-q-c_{n}\left(S x_{n}-u_{n}\right)\right] \| .
\end{aligned}
$$


From the nonexpansivity of $S$ and (3.4), we deduce that

$$
\begin{aligned}
& \limsup _{n \rightarrow \infty}\left\|S x_{n}-q-c_{n}\left(S x_{n}-u_{n}\right)\right\| \\
\leq & \limsup _{n \rightarrow \infty}\left[\left(1-c_{n}\right)\left\|x_{n}-q\right\|+c_{n}\left\|u_{n}-q\right\|\right] \\
\leq & d
\end{aligned}
$$

Because $T$ is asymptotically nonexpansive, by (2.1) we derive that

$$
\begin{aligned}
& \left\|T^{n} y_{n}-q-c_{n}\left(S x_{n}-u_{n}\right)\right\| \\
\leq & k_{n}\left\|y_{n}-q\right\|+c_{n}\left\|S x_{n}-q\right\|+c_{n}\left\|u_{n}-q\right\| \\
\leq & k_{n}\left(a_{n}^{\prime}\left\|x_{n}-q\right\|+b_{n}^{\prime} k_{n}\left\|x_{n}-q\right\|\right)+\left(c_{n}^{\prime} k_{n}+c_{n}\right) M+c_{n}\left\|x_{n}-q\right\| \\
\leq & \left(k_{n}^{2}+c_{n}\right)\left\|x_{n}-q\right\|+\left(c_{n}^{\prime} k_{n}+c_{n}\right) M
\end{aligned}
$$

for all $n \geq 1$. In view of (3.4)-(3.6) and (3.13), we conclude that

$$
\limsup _{n \rightarrow \infty}\left\|T^{n} y_{n}-q-c_{n}\left(S x_{n}-u_{n}\right)\right\| \leq d .
$$

On account of (3.10)-(3.12), (3.14) and Lemma 2.2, we see that

$$
\begin{aligned}
& \lim _{n \rightarrow \infty}\left\|S x_{n}-T^{n} y_{n}\right\| \\
= & \lim _{n \rightarrow \infty}\left\|\left[S x_{n}-q-c_{n}\left(S x_{n}-u_{n}\right)\right]-\left[T^{n} y_{n}-q-c_{n}\left(S x_{n}-u_{n}\right)\right]\right\| \\
= & 0,
\end{aligned}
$$

which implies that

$$
\lim _{n \rightarrow \infty}\left\|x_{n}-T^{n} y_{n}\right\|=0
$$

by (3.8). Clearly

$$
\left\|S x_{n}-x_{n}\right\| \leq\left\|S x_{n}-T^{n} y_{n}\right\|+\left\|x_{n}-T^{n} y_{n}\right\|, \quad \forall n \geq 1 .
$$

Thus (3.15) and (3.16) mean that

$$
\lim _{n \rightarrow \infty}\left\|S x_{n}-x_{n}\right\|=0 .
$$

It is easy to verify that

$$
\begin{aligned}
\left\|x_{n}-T^{n} x_{n}\right\| & \leq\left\|x_{n}-T^{n} y_{n}\right\|+k_{n}\left\|y_{n}-x_{n}\right\| \\
& \leq\left\|x_{n}-T^{n} y_{n}\right\|+k_{n}\left(a_{n}^{\prime}\left\|S x_{n}-x_{n}\right\|+b_{n}^{\prime}\left\|T^{n} x_{n}-x_{n}\right\|+c_{n}^{\prime} M\right)
\end{aligned}
$$


for each $n \geq 1$. It follows from (3.9) that there exists a positive integer $N$ such that $k_{n} b_{n}^{\prime}<1$ for all $n>N$. This yields that

$$
\left\|x_{n}-T^{n} x_{n}\right\| \leq \frac{1}{1-k_{n} b_{n}^{\prime}}\left(\left\|x_{n}-T^{n} y_{n}\right\|+k_{n}\left\|S x_{n}-x_{n}\right\|+M k_{n} c_{n}^{\prime}\right)
$$

for all $n \geq N$. According to (3.5), (3.10), (3.16)-(3.18) and (3.20), we conclude that

$$
\lim _{n \rightarrow \infty}\left\|x_{n}-T^{n} x_{n}\right\|=0 .
$$

It follows from (3.4)-(3.5), (3.17), (3.19) and Lemma 3.1 that

$$
\lim _{n \rightarrow \infty}\left\|x_{n}-T x_{n}\right\|=0 .
$$

This completes the proof.

Remark 3.3. Lemma 3.3 extends Lemma 3.3 in [10], Lemma 4 in [11] and Theorem 1 in [13].

Theorem 3.1. Let $E$ be a uniformly convex Banach space satisfying Opial's condition and $K$ be a nonempty closed convex subset of E. Let $S: K \rightarrow K$ be a nonexpansive mapping and $T: K \rightarrow K$ be an asymptotically nonexpansive mapping with a sequence $\left\{k_{n}\right\}_{n \geq 1} \subseteq[1, \infty)$ satisfying $\lim _{n \rightarrow \infty} k_{n}=1, F(S, T) \neq$ $\emptyset$, (3.4) - (3.6) and (3.8) - (3.10). Then the modified Ishikawa iteration sequence with errors $\left\{x_{n}\right\}_{n \geq 1}$ with respect to $S$ and $T$ given by (2.1) converges weakly to a common fixed point of $S$ and $T$.

Proof. It follows from Lemma 3.2 that $\left\{x_{n}\right\}_{n \geq 1}$ is bounded. Hence $\left\{x_{n}\right\}_{n \geq 1}$ has a subsequence $\left\{x_{n_{j}}\right\}_{j \geq 1}$, which converges weakly to $p$. Since $\left\{x_{n_{j}}\right\}_{j \geq 1} \subseteq K$ and $K$ is weakly closed, it follows that $p \in K$. In light of Lemma 2.1 we deduce that $I-T$ and $I-S$ are demiclosed at zero. Thus Lemma 3.3 ensures that $(I-T) p=$ $(I-S) p=0$. That is, $p \in F(S, T)$. Suppose that $\left\{x_{n}\right\}_{n \geq 1}$ does not converge weakly to $p$. Then there exists another subsequence $\left\{x_{m_{k}}\right\}_{k \geq 1}$ of $\left\{x_{n}\right\}_{n \geq 1}$ which converges weakly to some $q \neq p$. It is clear that $q \in F(S, T), \lim _{n \rightarrow \infty}\left\|x_{n}-p\right\|$ and $\lim _{n \rightarrow \infty}\left\|x_{n}-q\right\|$ exist. Let $a=\lim _{n \rightarrow \infty}\left\|x_{n}-p\right\|, b=\lim _{n \rightarrow \infty}\left\|x_{n}-q\right\|$. Because $E$ satisfies Opial's condition, we obtain that

$$
\begin{aligned}
& a=\liminf _{j \rightarrow \infty}\left\|x_{n_{j}}-p\right\|<\liminf _{j \rightarrow \infty}\left\|x_{n_{j}}-q\right\|= \\
& b=\liminf \inf _{k \rightarrow \infty}\left\|x_{m_{k}}-q\right\|<\liminf _{k \rightarrow \infty}\left\|x_{m_{k}}-p\right\|=a,
\end{aligned}
$$

which is a contradiction. Hence $p=q$ and $\left\{x_{n}\right\}_{n \geq 1}$ converges weakly to $p \in$ $F(S, T)$. This completes the proof. 
Lemma 3.4. Let $K$ be a nonempty bounded convex subset of a normed linear space E. Let $S: K \rightarrow K$ be a mapping and $T: K \rightarrow K$ be a uniformly L-Lipschitzian mapping. Then

$$
\begin{aligned}
\left\|x_{n+1}-T x_{n+1}\right\| \leq & \left\|x_{n+1}-T^{n+1} x_{n+1}\right\|+L\left(3+2 L+L^{2}\right)\left\|x_{n}-T^{n} x_{n}\right\| \\
& +L(L+1)\left(\left\|S x_{n}-x_{n}\right\|+c_{n}\left\|u_{n}-S x_{n}\right\|+L b_{n} c_{n}^{\prime}\left\|v_{n}-S x_{n}\right\|\right)
\end{aligned}
$$

for every $n \geq 1$, where $\left\{x_{n}\right\}_{n \geq 1}$ is defined by (2.1).

Proof. Put

$$
A_{n}=c_{n}\left(u_{n}-S x_{n}\right), \quad B_{n}=c_{n}^{\prime}\left(v_{n}-S x_{n}\right), \quad \forall n \geq 1 .
$$

Then the sequence $\left\{x_{n}\right\}_{n \geq 1}$ defined by (2.1) can be rewritten as

$$
\begin{aligned}
y_{n} & =\left(1-b_{n}^{\prime}\right) S x_{n}+b_{n}^{\prime} T^{n} x_{n}+B_{n}, \\
x_{n+1} & =\left(1-b_{n}\right) S x_{n}+b_{n} T^{n} y_{n}+A_{n}, \quad \forall n \geq 1 .
\end{aligned}
$$

The rest of the proof is exactly the same as that of Lemma 3.1, and is omitted. This completes the proof.

Remark 3.4. Lemma 3.4 is an improvement of Lemma 3 in [2] and Lemma 1.2 in [13].

Lemma 3.5. Let $K$ be a nonempty bounded closed convex subset of a real Banach space E. Let $S: K \rightarrow K$ be a nonexpansive mapping and $T: K \rightarrow K$ be a uniformly L-Lipschitzian and asymptotically nonexpansive mapping with a sequence $\left\{k_{n}\right\}_{n \geq 1} \subseteq[1, \infty)$ satisfying $\lim _{n \rightarrow \infty} k_{n}=1, F(S, T) \neq \emptyset$, (3.4)-(3.6), (3.8), (3.10) and

$$
\limsup _{n \rightarrow \infty} b_{n}^{\prime}<L^{-1}
$$

Then

$$
\lim _{n \rightarrow \infty}\left\|S x_{n}-x_{n}\right\|=\lim _{n \rightarrow \infty}\left\|x_{n}-T x_{n}\right\|=0,
$$

where $\left\{x_{n}\right\}_{n \geq 1}$ is defined by (2.1).

Proof. Let $\left\{A_{n}\right\}_{n \geq 1}$ and $\left\{B_{n}\right\}_{n \geq 1}$ be defined by (3.20) and $q \in F(S, T)$. Note that $K$ is a nonempty bounded closed convex subset and $\left\{x_{n}\right\}_{n \geq 1},\left\{y_{n}\right\}_{n \geq 1}$, $\left\{T^{n} x_{n}\right\}_{n \geq 1},\left\{T^{n} y_{n}\right\}_{n \geq 1},\left\{S x_{n}\right\}_{n \geq 1}$ are in $K$. Then there exists $r>0$ such that

$$
\begin{aligned}
& K \cup\left\{x_{n}-q, y_{n}-q, S x_{n}-q, S x_{n}-q+A_{n}, S x_{n}-q+B_{n},\right. \\
& \left.S x_{n}-u_{n}, S x_{n}-v_{n}, T^{n} x_{n}-q+A_{n}, T^{n} y_{n}-q+B_{n}, T^{n} y_{n}-q+A_{n}\right\} \subset B(\theta, r)
\end{aligned}
$$


for any $n \geq 1$. Using (3.21), Lemmas 2.3 and 2.4, we get that $(3.23)$

$$
\begin{aligned}
\left\|y_{n}-q\right\|^{2}-\left\|x_{n}-q\right\|^{2} \leq & \left(1-b_{n}^{\prime}\right) \| S x_{n} \\
& -q\left\|^{2}+b_{n}^{\prime}\right\| T^{n} x_{n}-q\left\|^{2}-\right\| x_{n}-q\left\|^{2}+2 r\right\| B_{n} \| \\
\leq & b_{n}^{\prime}\left(k_{n}^{2}-1\right)\left\|x_{n}-q\right\|^{2}+2 r\left\|B_{n}\right\|
\end{aligned}
$$

for each $n \geq 1$. It follows from (3.21), (3.23) and Lemma 2.4 that

$$
\begin{aligned}
\left\|x_{n+1}-q\right\|^{2}= & \left\|\left(1-b_{n}\right)\left(S x_{n}-q+A_{n}\right)+b_{n}\left(T^{n} y_{n}-q+A_{n}\right)\right\|^{2} \\
\leq & \left(1-b_{n}\right)\left\|S x_{n}-q+A_{n}\right\|^{2}+b_{n}\left\|T^{n} y_{n}-q+A_{n}\right\|^{2} \\
& -w_{2}\left(b_{n}\right) g\left(\left\|S x_{n}-T^{n} y_{n}\right\|\right) \\
\leq & \left(1-b_{n}\right)\left[\left\|S x_{n}-q\right\|^{2}+2\left\langle A_{n}, j\left(S x_{n}-q+A_{n}\right)\right\rangle\right] \\
& \left.+b_{n}\left\|T^{n} y_{n}-q\right\|^{2}+2\left\langle A_{n}, j\left(T^{n} y_{n}-q+A_{n}\right)\right\rangle\right] \\
& -w_{2}\left(b_{n}\right) g\left(\left\|S x_{n}-T^{n} y_{n}\right\|\right) \\
\leq & \left(1-b_{n}\right)\left(\left\|x_{n}-q\right\|^{2}+2 r\left\|A_{n}\right\|\right) \\
& +b_{n}\left(\left\|T^{n} y_{n}-q\right\|^{2}+2 r\left\|A_{n}\right\|\right) \\
& -b_{n}\left(1-b_{n}\right) g\left(\left\|S x_{n}-T^{n} y_{n}\right\|\right) \\
= & \left\|x_{n}-q\right\|^{2}+b_{n}\left(\left\|T^{n} y_{n}-q\right\|^{2}-\left\|y_{n}-q\right\|^{2}\right) \\
& +b_{n}\left(\left\|y_{n}-q\right\|^{2}-\left\|x_{n}-q\right\|^{2}\right) \\
& +2 r\left\|A_{n}\right\|-b_{n}\left(1-b_{n}\right) g\left(\left\|S x_{n}-T^{n} y_{n}\right\|\right) \\
\leq & \left\|x_{n}-q\right\|^{2}+b_{n}\left(k_{n}^{2}-1\right)\left\|y_{n}-q\right\|^{2}+b_{n} b_{n}^{\prime}\left(k_{n}^{2}-1\right)\left\|x_{n}-q\right\|^{2} \\
& +2 r b_{n}+2 r\left\|A_{n}\right\|-b_{n}\left(1-b_{n}\right) g\left(\left\|S x_{n}-T^{n} y_{n}\right\|\right)\left\|B_{n}\right\|
\end{aligned}
$$

for any $j\left(S x_{n}-q+A_{n}\right) \in J\left(S x_{n}-q+A_{n}\right)$ and $n \geq 1$. Because $\lim _{n \rightarrow \infty} k_{n}=1$, there exist a positive integer $M$ such that $k_{n} \leq 2$ for all $n \geq M$. Note that $\left\{x_{n}-q\right\}_{n \geq 1}$ and $\left\{y_{n}-q\right\}_{n \geq 1}$ belong to $B(\theta, r)$. Using (3.10) and (3.24), we get that

$$
\begin{aligned}
\left\|x_{n+1}-q\right\|^{2} \leq & \left\|x_{n}-q\right\|^{2}+6 r^{2}\left(k_{n}-1\right)+2 r^{2}\left(c_{n}^{\prime}+c_{n}\right) \\
& -a(1-b) g\left(\left\|S x_{n}-T^{n} y_{n}\right\|\right)
\end{aligned}
$$

for any $n \geq M$. This means that

$$
a(1-b) \sum_{n=M}^{\infty} g\left(\left\|S x_{n}-T^{n} y_{n}\right\|\right) \leq\left\|x_{1}-q\right\|^{2}+6 r^{2} \sum_{n=M}^{\infty}\left(k_{n}-1\right)+2 r^{2} \sum_{n=M}^{\infty}\left(c_{n}^{\prime}+c_{n}\right)<\infty
$$


by (3.4)-(3.6) and (3.10). It follows that

$$
\lim _{n \rightarrow \infty} g\left(\left\|S x_{n}-T^{n} y_{n}\right\|\right)=0 .
$$

Note that $g:[0, \infty) \rightarrow[0, \infty)$ is continuous and strictly increasing with $g(0)=0$. (3.26) yields that

$$
\lim _{n \rightarrow \infty}\left\|S x_{n}-T^{n} y_{n}\right\|=0 .
$$

On account of (3.8) and (3.27), we know that

$$
\lim _{n \rightarrow \infty}\left\|x_{n}-T^{n} y_{n}\right\|=0 .
$$

It follows from (3.27) and (3.28) that

$$
\lim _{n \rightarrow \infty}\left\|S x_{n}-x_{n}\right\|=0 .
$$

By virtue of (3.20) and (3.21), we deduce that for each $n \geq 1$

$$
\begin{aligned}
\left\|x_{n}-y_{n}\right\| & \leq\left\|x_{n}-T^{n} y_{n}\right\|+\left\|T^{n} y_{n}-y_{n}\right\| \\
& \leq\left\|x_{n}-T^{n} y_{n}\right\|+\left(1-b_{n}^{\prime}\right)\left\|S x_{n}-T^{n} y_{n}\right\|+b_{n}^{\prime} L\left\|x_{n}-y_{n}\right\|+\left\|B_{n}\right\|,
\end{aligned}
$$

which implies that

(3.30) $\left\|x_{n}-y_{n}\right\| \leq \frac{1}{1-b_{n}^{\prime} L}\left[\left\|x_{n}-T^{n} y_{n}\right\|+\left(1-b_{n}^{\prime}\right)\left\|S x_{n}-T^{n} y_{n}\right\|+c_{n}^{\prime} r\right], \forall n \geq 1$.

Thus (3.22) ensures that there exists a positive integer $N$ such that $b_{n}^{\prime}<L^{-1}$ for each $n \geq N$. By (3.5), (3.10), (3.27), (3.28) and (3.30), we obtain that

$$
\begin{aligned}
\left\|T^{n} x_{n}-x_{n}\right\| & \leq\left\|T^{n} x_{n}-T^{n} y_{n}\right\|+\left\|x_{n}-T^{n} y_{n}\right\| \\
& \leq L\left\|x_{n}-y_{n}\right\|+\left\|x_{n}-T^{n} y_{n}\right\| \\
& \leq \frac{L}{1-b_{n}^{\prime} L}\left[\left\|x_{n}-T^{n} y_{n}\right\|+\left(1-b_{n}^{\prime}\right)\left\|S x_{n}-T^{n} y_{n}\right\|\right. \\
& \left.+c_{n}^{\prime} r\right]+\left\|x_{n}-T^{n} y_{n}\right\| \\
& \rightarrow 0
\end{aligned}
$$

as $n \rightarrow \infty$. That is,

$$
\lim _{n \rightarrow \infty}\left\|T^{n} x_{n}-x_{n}\right\|=0 .
$$

In view of (3.4), (3.5), (3.10), (3.29), (3.31) and Lemma 3.4, we know that $\lim _{n \rightarrow \infty}$ $\left\|T x_{n}-x_{n}\right\|=0$. This completes the proof. 
Remark 3.5. Lemma 3.5 improves Lemma 4 in [2], Theorem 1 in [13] and Lemma 1.4 in [14].

Theorem 3.2. Let $E$ be a real uniformly convex Banach space, $K$ be a nonempty bounded closed convex subset of $E$. Let $S: K \rightarrow K$ be a nonexpansive mapping and $T: K \rightarrow K$ be a uniformly L-Lipschitzian and asymptotically nonexpansive mapping with a sequence $\left\{k_{n}\right\}_{n \geq 1} \subseteq[1, \infty)$ satisfying $\lim _{n \rightarrow \infty} k_{n}=1$, $F(S, T) \neq \emptyset$ and (3.8). Suppose that (3.4)-(3.6), (3.10) and (3.22) hold. If $T^{m}$ is semi-compact for some positive $m$, then the modified Ishikawa iteration sequence with errors $\left\{x_{n}\right\}_{n \geq 1}$ with respect to $S$ and $T$ given by (2.1) converges strongly to a common fixed point of $S$ and $T$.

Proof. Lemma 3.5 means that $\lim _{n \rightarrow \infty}\left\|S x_{n}-x_{n}\right\|=\lim _{n \rightarrow \infty}\left\|T x_{n}-x_{n}\right\|=$ 0 . Notice that

$\left\|T^{m} x_{n}-x_{n}\right\| \leq \sum_{i=0}^{m-1}\left\|T^{i+1} x_{n}-T^{i} x_{n}\right\| \leq\left(1+\sum_{i=1}^{m-1} k_{i}\right)\left\|T x_{n}-x_{n}\right\| \rightarrow 0$ as $n \rightarrow \infty$,

that is, $\lim _{n \rightarrow \infty}\left\|T^{m} x_{n}-x_{n}\right\|=0$. Since $T^{m}$ is semi-compact, there exists a subsequence $\left\{x_{n_{i}}\right\}_{i \geq 1} \subset\left\{x_{n}\right\}_{n \geq 1}$ such that $x_{n_{i}} \rightarrow q \in K$ as $i \rightarrow \infty$. By the continuity of $S$ and $T$, and Lemma 3.5, we conclude that

$$
\begin{aligned}
& \|S q-q\|=\lim _{i \rightarrow \infty}\left\|S x_{n_{i}}-x_{n_{i}}\right\|=\lim _{n \rightarrow \infty}\left\|S x_{n}-x_{n}\right\|=0 \\
& =\lim _{n \rightarrow \infty}\left\|T x_{n}-x_{n}\right\|=\lim _{i \rightarrow \infty}\left\|T x_{n_{i}}-x_{n_{i}}\right\|=\|T q-q\| .
\end{aligned}
$$

That is, $q$ is a common fixed point of $S$ and $T$ in $K$. From (3.25) we know that

$$
\left\|x_{n+1}-q\right\|^{2} \leq\left\|x_{n}-q\right\|^{2}+6 r^{2}\left(k_{n}-1\right)+2 r^{2}\left(c_{n}^{\prime}+c_{n}\right)
$$

for all $n \geq 1$. Then (3.4)-(3.6), (3.10) and Lemma 2.5 guarantee that $\lim _{n \rightarrow \infty} \| x_{n}-$ $q \|^{2}=0$. That is, $\lim _{n \rightarrow \infty} x_{n}=q$. This completes the proof.

Remark 3.6. Theorems 3.1 and 3.2 extend, improve and unify Theorems 1.1 and 1.2 in [2], Theorems 1 and 2 in [10], Theorems 2 and 3 in [11], Theorem 1.5 in [13] and Theorems 2.1 and 2.2 in [14] and in the following ways:

(i) the identity mapping in [2], [10], [11], [13] and [14] is replaced by the more general nonexpansive mapping;

(ii) the usual modified Mann iteration methods in [14], the usual modified Ishikawa iteration methods in [11] and [13] and the usual modified Ishikawa iterations methods with errors in [2] and [10] are extended to the modified Ishikawa iteration methods with errors with respect to a pair of mappings; 
(iii) the conditions (3.8) and (3.10) are weaker than the condition

$$
0<\varepsilon \leq a_{n} \leq 1-\varepsilon, \quad \forall n \geq 1
$$

imposed on Theorems 1.1 and 1.2 in [2], Theorem 1 in [10], Theorems 2 and 3 in [11] and Theorem 1.5 in [13];

(iv) the Hilbert space in [13] is extended to the more general uniformly convex Banach space.

The following example shows that Theorem 3.2 extend substantially Theorem 1.2 in [2], Theorem 2 in [10], Theorem 3 in [11], Theorem 1.5 in [13] and Theorem 2.2 in [14].

Example 3.1. Let $E$ be the real line with the usual norm $|\cdot|$ and let $K=[-1,1]$. Define $S$ and $T: K \rightarrow K$ by

$$
T x=\begin{array}{ll}
-2 \sin \frac{x}{2}, & x \in[0,1], \\
2 \sin \frac{x}{2}, & x \in[-1,0)
\end{array} \quad \text { and } \quad S x=\begin{array}{ll}
x, & x \in[0,1], \\
-x, & x \in[-1,0)
\end{array} .
$$

Obviously $F(S, T)=\{0\}$ and $T$ is semi-compact. Now we check that $T$ is nonexpansive. In fact, if $x$ and $y \in[0,1]$ or $x$ and $y \in[-1,0)$, then

$$
|T x-T y|=2\left|\sin \frac{x}{2}-\sin \frac{y}{2}\right| \leq|x-y|
$$

if $x \in[0,1]$ and $y \in[-1,0]$ or $x \in[-1,0)$ and $y \in[0,1]$, then

$$
|T x-T y|=2\left|\sin \frac{x}{2}+\sin \frac{y}{2}\right|=4\left|\sin \frac{x+y}{4} \cos \frac{x-y}{4}\right| \leq|x+y| \leq|x-y| .
$$

That is, $T$ is nonexpansive. It follows that $T$ is uniformly 1-Lispchitzian and asymptotically nonexpansive with $k_{n} \equiv 1$ for each $n \geq 1$. Similarly, we can verify that $S$ is nonexpansive. In order to show that $S$ and $T$ satisfy (3.8), we have to consider the following cases:

Case 1. Suppose that $x$ and $y \in[0,1]$. It follows that

$$
|x-T y|=\left|x+2 \sin \frac{y}{2}\right|=|S x-T y|
$$

Case 2. Suppose that $x$ and $y \in[-1,0)$. Then we easily see that

$$
|x-T y|=\left|x-2 \sin \frac{y}{2}\right| \leq\left|-x-2 \sin \frac{y}{2}\right|=|S x-T y|
$$

Case 3. Suppose that $x \in[-1,0)$ and $y \in[0,1]$. It is easy to verify that

$$
|x-T y|=\left|x+2 \sin \frac{y}{2}\right| \leq\left|-x+2 \sin \frac{y}{2}\right|=|S x-T y|
$$


Case 4. Suppose that $x \in[0,1]$ and $y \in[-1,0)$. It follows that

$$
|x-T y|=\left|x-2 \sin \frac{y}{2}\right|=|S x-T y| .
$$

Hence (3.8) is satisfied. Suppose that $\left\{u_{n}\right\}_{n \geq 1},\left\{v_{n}\right\}_{n \geq 1}$ are given sequences in $K$,

$$
\begin{aligned}
& a=\frac{3}{5}, b=\frac{6}{7}, a_{n}=\frac{2}{5}-\frac{1}{3 n+2}-\frac{1}{6 n^{2}}, a_{2 n}^{\prime}=1-\frac{1}{3 n}-\frac{1}{2 n^{2}+3}, \\
& a_{2 n-1}^{\prime}=\frac{1}{2}-\frac{1}{3 n+2}-\frac{1}{2 n^{2}+3}, b_{n}=\frac{3}{5}+\frac{1}{3 n+2}, b_{2 n}^{\prime}=\frac{1}{3 n} \\
& b_{2 n-1}^{\prime}=\frac{1}{3 n+2}+\frac{1}{2}, c_{n}=\frac{1}{6 n^{2}} \text { and } c_{2 n}^{\prime}=c_{2 n-1}^{\prime}=\frac{1}{2 n^{2}+3}
\end{aligned}
$$

for any $n \geq 1$. Thus the conditions of Theorem 3.2 are fulfilled. Therefore, the modified Ishikawa iteration sequences with errors $\left\{x_{n}\right\}_{n \geq 1}$ with respect to $S$ and $T$ defined by (2.1) converges strongly to 0 . But the results in [2] and [10], [11], [13] and [14] are not applicable because $S \neq I$.

\section{ACKNOWLEDGMENT}

The authors thank the referee for his valuable suggestions for the improvement of the paper.

\section{REFERENCES}

1. R. P. Agarwal, Y. J. Cho, J. Li and N. J. Hunag, Stability of iterative procedures with errors approximating common fixed points for a couple of quasi-contractive mappings in q-uniformly smooth Banach spaces, J. Math. Anal. Appl. 272 (2002), 435-447.

2. S. S. Chang, On the approximation problem of fixed points for asymptotically nonexpansive mappings, Indian J. pure appl. Math., 32 (2001), 1297-1307.

3. S. S. Chang, Some problems and results in the study of nonlinear analysis, Nonlinear Anal. T. M. A., 30 (1997), 4197-4208.

4. K. Goebel and W. A. Kirk, A fixed point theorem for asymptotically nonexpansive mappings, Proc. Amer. Math. Soc., 35 (1972), 171-174.

5. J. Gornicki, Weak convergence theorems for asymptotically nonexpansive mappings in uniformly convex Banach spaces, Comment. Math. Univ. Carolina., 30 (1989), 249-252.

6. Z. Liu, J. K. Kim and K. H. Kim, Convergence theorems and stability problems of the modified Ishikawa iterative sequences for strictly successively hemicontractive mappings, Bull. Korean Math. Soc., 39 (2002), 455-469. 
7. Z. Liu, J. K. Kim and S. A. Chun, Iterative approximation of fixed points for generalized asymptotically contractive and generalized hemicontractive mappings, PanAmerican Math. J., 12 (2002), 67-74.

8. Z. Liu and S. M. Kang, Weak and strong convergence for fixed points of asymptotically nonexpansive mappings, Acta Math. Sinica 20 (2004), 1009-1018.

9. Z. Opial, Weak convergence of the sequence of successive approximations for nonexpansive mappings, Bull. Amer. Math. Soc., 73 (1967), 591-597.

10. M. O. Osilike and S. C. Aniagbosor, Weak and strong convergence theorems for fixed points of asymptotically nonexpansive mappings, Math. Comput. Modell., 32 (2000), 1181-1191.

11. B. E. Rhoades, Fixed point iteration for certain nonlinear mappings, J. Math. Anal. Appl., 183 (1994), 118-120.

12. B. E. Rhoades, Comments on some iteration processes with errors, Fixed Point Theory and Applications, Vol. 5, (Eds. Y. J. Cho, J. K. Kim and S. M. Kang), Nova Science Publishers, New York, 2004, pp. 125-126.

13. J. Schu, Iterative construction of fixed points of asymptotically nonexpansive mappings, J. Math. Anal. Appl., 158 (1991), 407-413.

14. J. Schu, Weak and strong convergence of fixed points of asymptotically nonexpansive mappings, Bull. Austral. Math. Soc., 43 (1991), 153-159.

15. H. K. Xu, Inequalities in Banach spaces with applications, Nonlinear Anal. T. M. A., 16 (1991), 1127-1138.

\author{
Zeqing Liu \\ Department of Mathematics, \\ Liaoning Normal University, \\ P. O. Box 200 \\ Dalian, Liaoning 116029, \\ People's Republic of China \\ E-mail: zeqingliu@dl.cn \\ Chi Feng \\ Department of Science, \\ Dalian Fisheries College, \\ Dalina, Liaoning, 116023, \\ People's Republic of China \\ Jeong Sheok Ume* \\ Department of Applied Mathematics, \\ Changwon National University, \\ Changwon 641-773, Korea \\ E-mail: jsume@changwon.ac.kr
}


Shin Min Kang

Department of Mathematics and Research Institute of Natural Science,

Gyeongsang National University,

Chinju 660-701, Korea

E-mail: smkang@nongae.gsnu.ac.kr 